\title{
O feito à mão no Design Brasileiro: a revalorização das artes manuais no Design de Produto e Design Editorial entre 2010-2020
}

\author{
Handmade Brazilian Design: the revalorization of arts and crafts in Product Design \\ and Editorial Design through 2010-2020
}

\author{
Dânica Vasques Fagundes Machado, Maria Luísa Acioli Falcão de Alencar
}

Artesanato, Feito à mão, Design de Produto, Design Editorial, Consumo Consciente

\begin{abstract}
Neste trabalho, abordamos a revalorização das artes manuais no do design brasileiro dos últimos 10 anos, utilizando recortes dos campos do design de produto e editorial. Por meio do referencial teórico, mapeamento das produções e coleta de dados, trata-se de questões relativas à definição de artesanato e artes manuais, as mãos como ferramenta de trabalho, associação entre design e artesanato, além da ampliação de movimentos relacionados ao fazer manual, como o "faça você mesmo", consumo consciente e práticas coletivas de produção. Considerando o contexto histórico do design brasileiro, destacamos os movimentos de contracultura para demonstrar a reassociação das artes manuais ao design como ligada à insatisfação com modelos de produção e consumo vigentes, a busca da individualidade e do tempo de contemplação. No cenário contemporâneo, podemos colocar o capitalismo tardio, consumo de acumulação e a sociedade baseada na produtividade como pontos que levam à busca por atividades que quebrem este ritmo e tragam significado ao consumo.
\end{abstract}

\section{Craftwork, Handmade, Product Design, Editorial Design, Conscious Consumption}

This paper approaches the revalorization of arts and crafts in Brazilian design over the last 10 years, considering the fields of product design and editorial design. Through a theoretical basis, research on the production and data collection, we tackle issues such as the definition of craftwork, the hands as a work tool, the association of design and craftwork, along with the expansion of movements that promote handmade crafts, DIY - do it yourself, conscious consumption and collective work. Bearing in mind the historical context of Brazilian design, we highlight the counterculture movements to demonstrate that a reassociation between handcrafts and design is connected to a dissatisfaction towards the prevailing production and consumption practices, a desire of individuality and contemplation time. In the current state, we can take into account that late capitalism, cumulative consumption and a society based on productivity motivate people to seek activities that break this intense life rhythm and bring meaning to the process of consumption.

\section{Introdução}

O trabalho artesanal é incumbido de grande carga política e cultural, especialmente ao considerarmos seu percurso ao longo da história da sociedade. Falar do ofício artesão é ter em conta que, pré-Revolução Industrial, o trabalho à mão era a única alternativa para manufatura, tanto de objetos particulares quanto de utensílios cotidianos.

Anais do $10^{\circ} \mathrm{CIDI}$ e $10^{\circ} \mathrm{CONGIC}$

Kelli C.A.S. Smythe, Rafael de Castro Andrade (orgs.)

Sociedade Brasileira de Design da Informação - SBDI

Curitiba | Brasil | 2021
Proceedings of the $10^{\text {th }} \mathrm{CIDI}$ and $10^{\text {th }}$ CONGIC

Kelli C.A.S. Smythe, Rafael de Castro Andrade (orgs.)

Sociedade Brasileira de Design da Informação - SBDI Curitiba | Brazil | 2021 
No cenário de mudanças nos sistemas de produção, especialmente após o século XVIII, o trabalho artesanal passa a ter papel secundário, associado apenas ao seu caráter instrumental. O artesão não era visto como capaz de unir o "fazer" e o "pensar", sendo desvinculado do papel de artista e criador. Contrário a esta ideia, Flusser (1985) argumenta que o "fazer com técnica", diferente do fazer mecânico e instrumental, é um método de agir e pensar sobre o mundo, à medida que propõe reflexões e busca diferentes caminhos e soluções. Neste sentido, o ato de "pensar" e de "fazer" estão, necessariamente, associados.

A figura do designer surge a partir dos Séculos XIX e XX, sendo o profissional que lida e dá forma à matéria, se utilizando das potencialidades das máquinas e tecnologias, em substituição ao artesão - que Ferrara (2011, pp. 71-72) distingue como aquele que transforma a mão, o ritmo e a força em suas ferramentas. No contexto do design brasileiro, a formalização do ofício, cujo marco é a fundação da ESDI, em 1963, teve influência do design alemão e da estética racionalista e funcionalista do Estilo Internacional. Prevaleceram os ideais de "boa forma" e "bom design", buscando a adequação ao momento de industrialização do Brasil durante 1950 a 1970. Borges (2011, p. 31), explica que a preferência pelo produto feito à máquina aconteceu em detrimento da rica herança cultural que estava presente em nossos artefatos. Seria uma tentativa de superar "o passado de atraso, subdesenvolvimento e pobreza", da qual a manualidade fazia parte.

Por volta dos anos 1980 e 1990, iniciou-se um processo de ressurreição dos ofícios manuais, há décadas limitados ao campo da arte popular. O desejo de rebelião ao padrão dos objetos em série, da neutralidade e racionalidade faria surgir movimentos como o PósModernismo, resgatando a emoção e a intuição. A reassociação do design ao artesanato, desta forma, pode ser justificada tanto pela intenção de superar a máxima "forma segue função", reunindo a utilidade ao ornamento e à estética; quanto pela fadiga do consumidor frente a produtos industrializados e impessoais.

Ao pensarmos no contemporâneo, encaramos uma conjuntura de intenso ritmo de vida, pautado por uma sociedade de desempenho. Han (2015) aponta que o ideal da superprodutividade cria pessoas que se afastam do olhar atento e contemplativo, se tornando "multitarefas" - um estado de atenção que se preocupa simultaneamente com diversas tarefas e informações. Este modo de viver nos afasta de atividades associadas à atenção, à paciência e à uma temporalidade mais lenta. Diante disto, observamos que, nos últimos 10 anos, há uma mobilização pela revalorização de ofícios manuais no design, semelhante ao ocorrido nos anos 1980 e 1990. Isto sugere uma tentativa de resgatar experiências analógicas, reais, individualizadas e que respeitem o tempo natural do trabalho humano.

Neste artigo, buscamos compreender a reinserção das artes manuais no design brasileiro, considerando os campos do design de produto e design editorial. Há um exercício comparativo entre o contexto histórico pós-modernista dos anos 1980 e a conjuntura atual, compreendida nos últimos 10 anos. Consequentemente, surgem reflexões sobre o consumo consciente e a cultura do "feito à mão". Para entender estas questões, utilizou-se o aporte bibliográfico sobre arte, artesanato, design e tecnologia; mapeamento das produções, coleta e análise de dados, 
visando traçar relações entre as produções e manifestações artesanais em dois diferentes campos do design. Por fim, trazemos exemplos de produções contemporâneas relevantes para a temática de pesquisa.

\section{Ofício artesanal}

O ofício manual representa a possibilidade de conexão com os limites do próprio corpo, evolução através da técnica, do uso de ferramentas e aperfeiçoamento de um estilo pessoal. Sennett (2009, pp. 30-31) elabora sobre as recompensas emocionais adquiridas a partir do trabalho artesanal. Existiriam dois fatores principais nesta relação: a satisfação em perceber o fruto do trabalho concretamente e o orgulho por fazê-lo bem. Ao longo de uma evolução no ofício, as mudanças causadas por determinados estímulos à matéria, formas de manuseio e uso da força incitam reflexões quanto ao processo em si. Além disso, as peculiaridades das mãos como ferramenta de trabalho trazem um teor único à produção, dotando o objeto de individualidade.

No contexto brasileiro e da América Latina, o artesanato carrega de forma presente a ideia de coletividade, do saber passado por gerações e não reproduzido em série (Borges, 2011, p. 25). Destacamos que o trabalho artesanal no Brasil é formado, em sua maioria, por grupos com baixa escolaridade e baixa renda. Assim, a separação entre o artesanal e o industrial também revela a divisão entre uma produção da "elite" e do "povo", associando à elite um fazer artístico fruto de reflexões e, ao povo, a função de "executar". Tais questões nos ajudam a entender por que o artesanato é muitas vezes reservado ao lugar de arte popular e colocado em oposição às belas artes. Neste ponto, Mário Pedrosa (1985) argumenta que tais definições e códigos foram criados na sociedade capitalista para diferenciar as classes sociais e suas produções.

Observamos que as definições de artesanato e artesão são pontos de divergência que refletem questões sociopolíticas. Neste espaço, consideramos a figura do artífice elaborada por Sennett (2009): o trabalhador que possui a habilidade técnica e capacidade de concretizar ideias, se satisfazendo ao realizar um bom trabalho. Ademais, entendemos o artesanato como a produção de artigos feitos totalmente à mão ou com poucas interferências mecânicas, onde a contribuição manual do artesão é um aspecto fundamental na fabricação.

A importância de tais delimitações está no entendimento do processo de produção, considerando o pensamento de Canclini (2015), que o artesanato precisa ser estudado como processo e não como resultado. Manning (2016), aliada a esta ideia, argumenta que a arte também diz respeito ao processo e não ao objeto em si. Consequentemente, nos apoiamos na ideia de que arte e artesanato são capazes de ultrapassar a técnica e criar significados; assim, também utilizamos "artes manuais" para nos referir ao trabalho artesanal.

Atualmente as tecnologias, cada vez mais presentes no cotidiano das pessoas, assim como a sociedade em rede, podem ser aliadas no compartilhamento de modos de fazer artísticos e manuais. Produtores, artistas e artesãos utilizam das ferramentas online para a difusão de seus 
projetos, agregando a seus discursos questões já mencionadas, como a valorização do trabalho artesanal, o papel do artesão e as relações entre arte e artesanato.

As redes sociais, acompanhando este movimento, atuam como facilitadoras de ideais do fazer manual, como o "faça você mesmo", que tem se tornado cada vez mais presente nos conteúdos disponibilizados em plataformas online. São inúmeros os vídeos e postagens em forma de tutoriais, que ensinam e propõem atividades como pintura, desenho, bordado e técnicas de impressão manual. Entre 2010 e 2016, termos como "faça você mesmo" e "DIY"1 tiveram um aumento considerável no número de buscas no Google ${ }^{2}$. No Instagram são mais 65 milhões de conteúdos ${ }^{3}$ que utilizam a hashtag "DIY". Estes materiais permitem que mesmo designers e artistas tenham contato com outras ferramentas e técnicas que podem ser incorporadas às suas produções.

Além da procura por atividades manuais, entra em questão a busca por um consumo consciente, conduzido por questões emergentes - indagações sobre como os objetos são produzidos, onde e por quem. A retomada de práticas artesanais, considerando o processo de globalização, mostra a valorização das diferenças e da identidade de culturas locais. Isto permitiu, também, mudanças econômicas que estimularam a criação da chamada economia criativa. (Moura, 2010)

Lipovetsky e Serroy (2015) observam ser cada vez mais presente a necessidade de atribuir sentido àquilo que consumimos, pois atualmente esta prática é pautada pelo significado, e não mais por questões objetivas ou necessidades. Discursos como o "compre de quem faz" e "apoie pequenos produtores" trazem consigo a preocupação com as condições em que os produtos são fabricados. Desta forma, objetos feitos manualmente e por pequenos produtores são valorizados, carregando em si o imaginário da produção coletiva do artesanato e levantando questões afetivas e de memória. Estreitam-se relações entre o consumidor e o produtor, atribuindo novos sentidos e senso de comunidade ao ato de adquirir coisas.

\section{Atravessamentos entre as artes manuais e o Design}

Com a consolidação do modelo capitalista de consumo, o incentivo à produção em massa e funcionalização do design levaram à padronização dos produtos industriais. Assim, no final dos anos $1980^{4}$, o descontentamento com essa modalidade de produção - que estandardiza o produto e contribui com ideais de consumo desenfreado - fez surgir movimentos de contracultura relacionados à fuga de padrões, experimentação visual e material, além do resgate de soluções analógicas. Como menciona Ferrara (2011, pp. 76-77), o design volta à

\footnotetext{
${ }^{1}$ Sigla do termo Do It Yourself, em português "Faça você mesmo".

${ }^{2}$ De acordo com o Google Trends. Data de busca: 8 de maio de 2021.

${ }^{3}$ Dados coletados no Instagram. Data de busca: 8 de maio de 2021

${ }^{4} \mathrm{O}$ contexto geopolítico da época, com a difusão do processo de globalização, também agiu no desenvolvimento de um movimento pós-moderno. A interação entre diferentes realidades socioculturais proporcionou caminhos à adoção de ideais múltiplos.
} 
posição de único, com qualidades artesanais que evidenciam não mais a função do objeto, mas as particularidades do projeto.

No contexto histórico do pós-modernismo brasileiro, Moraes (2005, p. 179) coloca que, embora a produção da época não seja significativa, possui valor ao ter sido precursora de um design propriamente brasileiro, aceitando o pluralismo ético e estético característico da cultura local. No design de produto, a aproximação com o artesanato se deu, no final dos anos 80 , através de um projeto de reconhecimento da cultura brasileira e suas multiplicidades. Por iniciativa e interesse dos próprios designers, surgiu a ideia de percorrer o Brasil conhecendo tradições artesanais associadas às regiões, propondo métodos e técnicas que pudessem diversificar a produção e ampliar as possibilidades de mercado. A intenção era buscar soluções que agregassem, mas não interferissem nas tradições locais. Neste sentido, o design era responsável por ajudar a comunicar os valores desses objetos (Borges, 2011). Apesar dos projetos de cooperação entre designers e artesãos, não existiam instituições governamentais que respaldassem o movimento.

Nos anos 1990, surgiram aportes institucionais para estas atividades, ou seja, organizações responsáveis por promover políticas públicas para o artesanato; foram criados setores de mapeamento, capacitação e fortalecimento dessas práticas. Da mesma maneira, emergiram iniciativas que mostrassem ao público o trabalho artesanal associado às produções de design e arte - tais quais exposições e catálogos impressos. Em 1997, o A CASA - Museu do Objeto Brasileiro, foi criado com a intenção de ampliar o conhecimento sobre essas produções e projetos. O museu, que segue ativo, recebe diversas mostras sobre artes manuais, cerâmica e joalheria, além de promover encontros, workshops e palestras sobre o assunto.

No design editorial, viu-se surgir, por volta de 1970, o movimento da Poesia Marginal, composto por jovens poetas que desejavam publicar seus trabalhos de forma autônoma e espontânea, assumindo o papel de autores-editores. Com poucos recursos disponíveis, estes produtores buscavam alternativas acessíveis e de baixo custo, utilizando métodos de impressão rudimentares e adotando a manualidade e o conceito "faça você mesmo". O emprego do aparelho mimeógrafo como ferramenta copiadora tornou popular a denominação 'Geração Mimeógrafo' a este grupo de autores e produtores.

Em período semelhante, especialmente entre 1970 e 1990, se destacam as manifestações punk e grunge, que motivaram a produção independente, autoral e artesanal por meio das fanzines. Trata-se de impressos editados pelos fãs dos conjuntos musicais, assumindo esta modalidade de produção como alternativa para expor ideias e temas que não seriam facilmente inseridos na mídia tradicional. Havia uma estética muito característica das técnicas utilizadas como a colagem, datilografia, desenho e reprodução em fotocópias - que, pela peculiaridade, ficou marcada no imaginário social.

Trazendo a reflexão ao momento atual, saltamos de uma sociedade de produção industrial mecânica, ainda sentindo os primeiros efeitos do intercâmbio cultural e informacional promovido pela globalização; passando à sociedade contemporânea, pautada pelo uso do digital, as tecnologias da informação, urgência e agilidade nas relações. 
Han (2015) e Crary (2014) situam o cenário da atualidade como uma fase do capitalismo tardio onde busca-se cada vez mais a eficiência e automação. Crary (2014) alerta sobre o ritmo insustentável da vida contemporânea, onde são cada vez mais aceitáveis ações como o trabalho sem pausas, incentivo ao consumo de acumulação, superabundância de serviços e imagens. A sobrevivência neste ambiente ignora necessidades essenciais do ser humano, como o sono e o tempo para contemplação. Em outro ponto, Han (2015) coloca que a sociedade baseada no desempenho cria pessoas que, cada vez mais, buscam resultados imediatos e em grande quantidade. $\mathrm{O}$ autor sugere que a principal característica dessa sociedade é o "multitarefas". A pessoa multitarefa está sempre em contato com as mais diversas informações e funções ao mesmo tempo, deixando de lado a atenção profunda e direcionada às atividades, algo indispensável, por exemplo, para as produções manuais.

Neste contexto, a necessidade do trabalho com as mãos está em recuperar uma relação mais saudável com o fazer e o consumo, além de práticas mais saudáveis e humanas com o tempo, o material e o trabalho em si. De maneira semelhante ao ocorrido durante a agitação dos movimentos de contracultura, a reassociação entre design e artes manuais se mostra relacionada ao descontentamento com práticas vigentes na sociedade contemporânea. Percebemos, então, este movimento na produção atual, dentro dos recortes de pesquisa.

Pensando na elaboração de objetos e no design de produto, é cada vez mais presente o diálogo entre áreas como a moda, arte e artesanato. Questões como diversidade, confronto, interação entre diversas culturas e pensamentos, são pontos chave desta modalidade de produção (Moura, 2010); cujo modo de atuação reitera a noção de coletivo, propondo uma atuação em grupos que se associa ao imaginário do artesanato.

Nos últimos 10 anos, discursos atrelados à sustentabilidade, consumo consciente e coletividade têm se tornado fundamentais nas áreas que abarcam o design de produto. $O$ projeto Jardim Secreto, localizado em São Paulo, promove feiras públicas que reúnem pessoas e artesãos de todo o país. A iniciativa busca fomentar produções e ações coletivas que proponham a sustentabilidade e o impulsionamento da economia criativa. De 2013 a 2019, promoveram a Feira Jardim Secreto, um espaço de compartilhamento, integração e valorização das artes manuais em seus mais diversos formatos. A curadoria do projeto contempla produtores que utilizem matéria prima responsável, possuam uma produção local, inovadora e feita à mão; trazendo a noção de um comércio justo que valoriza as pessoas envolvidas na fabricação.

Outro braço do Jardim Secreto é o Galpão Jardim Secreto, criado em 2019. Trata-se de um espaço coletivo, responsável por reunir mercadorias provenientes de mais de 130 marcas independentes, designers e artesãos. Dentre eles, podemos observar o uso de técnicas como cerâmica, bordado, crochê e pintura; apresentadas nos mais diversos produtos, como utensílios domésticos e roupas. No espaço, também são promovidos eventos, cursos e oficinas que ampliam e difundem as possibilidades do feito à mão.

Já no campo editorial, podemos colocar que a reinserção das artes manuais está, atualmente, presente no cenário das publicações independentes. Semelhante aos poetas marginais e editores de fanzines, produtores independentes se caracterizam pelo desejo de 
autonomia - tanto desprendimento à ideia tradicional de mercado, quanto a liberdade de publicar o que se deseja, da maneira que se deseja. Não significa que não seguem uma linha mercadológica, porém, acima do lucro, preza-se pela qualidade do produto e liberdade de publicação. Estes profissionais têm uma relação afetiva com o impresso, considerando sua materialidade e potencial de ser um manifesto do papel, expondo o trabalho do artista.

Neste ponto, Lupton (2008) destaca o valor do livro artesanal ao considerá-lo uma ótima maneira de designers e artistas exporem suas habilidades técnicas, produzindo edições primorosas. Para isto, é preciso controlar a produção por meio de escolhas como o método de encadernação, tipo de papel e outros. Em sentido semelhante, Munari (2016), ao realizar experimentos com a "ilegibilidade do livro", explorando a linguagem visual e tátil, afirma a importância de testar vários tipos de papel, formato, encadernação e texturas. $O$ teor experimental deste método parece remeter à produção independente, já que supostamente estes editores possuem maior liberdade criativa, em comparação às práticas do mercado tradicional.

É comum que haja um resgate de técnicas tidas como antigas - encadernação artesanal, impressão com tipos móveis e outros procedimentos que expressam, também, a relação entre a arte e o manual, como gravura e linotipia. Ao utilizarem mecanismos que na história da produção editorial eram tidos como o método convencional de fabricação, estes produtores exercem, também, um trabalho de resgatar a própria memória gráfica. Para Muniz Jr. (2016, pp. 197) o retorno da artesanalidade proporciona "singularidade na vida cultural através da materialidade e artesanalidade do livro".

A partir dos anos 2010, especialmente em São Paulo, houve grande crescimento do cenário editorial independente, refletido no aumento de feiras de publicações, bancas que comercializam estes impressos e outros eventos que visam fomentar a cultura deste modelo de produção. Dentre alguns eventos populares estão a Feira Tijuana (surgiu em 2009 e até então, está suspensa devido à pandemia de COVID-19), a Feira Plana (2013-2018) e a Feira Miolos (2014-atual), sendo esta última a principal em atividade no país, acontecendo normalmente na Biblioteca Mário de Andrade, em São Paulo e, atualmente, seguindo em versão online. A gênese destas feiras está em proporcionar um ambiente de trocas entre os agentes do meio, incentivando parcerias entre os produtores, promovendo o escambo de habilidades técnicas e favorecendo a relação entre produtor e consumidor, já que este pode conhecer de perto o produto, como foi feito e os ideais da editora/produtora.

Embora haja destaque ao objeto impresso, as feiras independentes funcionam, também, como uma vitrine para divulgação de objetos gráficos adjacentes e objetos artesanais, como cartazes, zines, ímãs, bordados e pinturas.

\section{Design feito à mão}

Partindo da reflexão sobre um design contemporâneo que retoma relações com o fazer manual, elucidando a importância do contexto em que o produto artesanal é valorizado, trazemos casos de produtores e projetos onde, dentro dos respectivos campos do design de 
produto e design editorial, o uso das mãos como ferramenta representa um diferencial na construção estética e simbólica dos objetos. Dentro da particularidade de cada projeto, são perceptíveis o caráter técnico e o teor de individualidade proporcionado por cada produtor.

O T44 studio, formado por Dennys Tormen e Patrick Tormen, é um estúdio de design criado em 2014, em Balneário Camboriú. Tem uma produção cuja proposta é dialogar e entrelaçar o design com técnicas de produção manual, através de produtos autorais e majoritariamente feitos à mão. A preocupação com os modos de fabricação se evidencia na produção em pequenos lotes ou peças únicas. Além disso, a dupla afirma que as peças são resistentes, duráveis e funcionais.

Em parceria com a artista Luiza Caldari, criaram a coleção Acampa, uma série de cadeiras inspiradas em campings, dobráveis e com assento em couro ecológico. Os encostos, que podem ser utilizados em ambos os lados, foram feitos com uma técnica de tapeçaria chamada tufting, que consiste em "bordar" no tecido com uma ferramenta mecanizada. Os esboços das tapeçarias foram feitos pela artista, assim como a execução do trabalho; já as estruturas foram feitas em aço tubular pelo estúdio. As peças demonstram a versatilidade e as possibilidades dos objetos têxteis manuais.

Figuras 1 e 2: Cadeiras da série Acampa. Studio T44 + Luiza Caldari. Fonte: Luiza Caldari. Disponível em luizacaldari.com/collections/serie-acampa
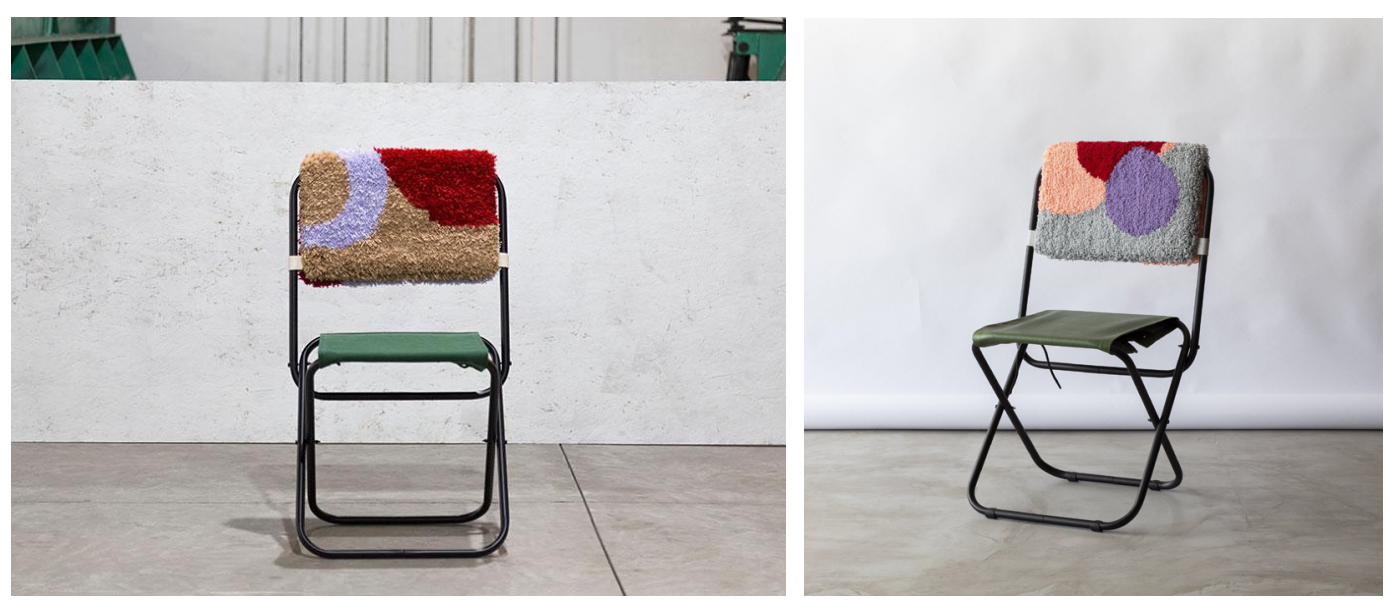

No projeto do banco UNA, parceria com o artesão e designer Patrick Vargas, explora-se a união da estrutura rígida do aço com uma técnica de tecelagem que utiliza unicamente cordas e as mãos. O objeto tem estrutura em aço elaborada por Patrick Tormen, do T44, e no assento foi tramado, com corda náutica, um padrão geométrico autoral criado por Patrick Vargas.

Outro ponto importante para pensar o uso dessas técnicas nos projetos do estúdio são os vídeos disponibilizados nas redes sociais. Assim como de outros projetos, é possível assistir o processo de criação do banco UNA através de um vídeo que mostra o artista tramando a corda e construindo o objeto. Além de ser um recurso interessante para tornar acessível os modos de fazer do grupo, os vídeos demonstram a preocupação em mostrar, para aqueles que acompanham os trabalhos, como as peças são feitas. 
Figuras 3 e 4: Banco UNA. Studio T44 + Patrick Vargas. Fonte: Studio T44. Disponível em t44.com.br/products/banco-una
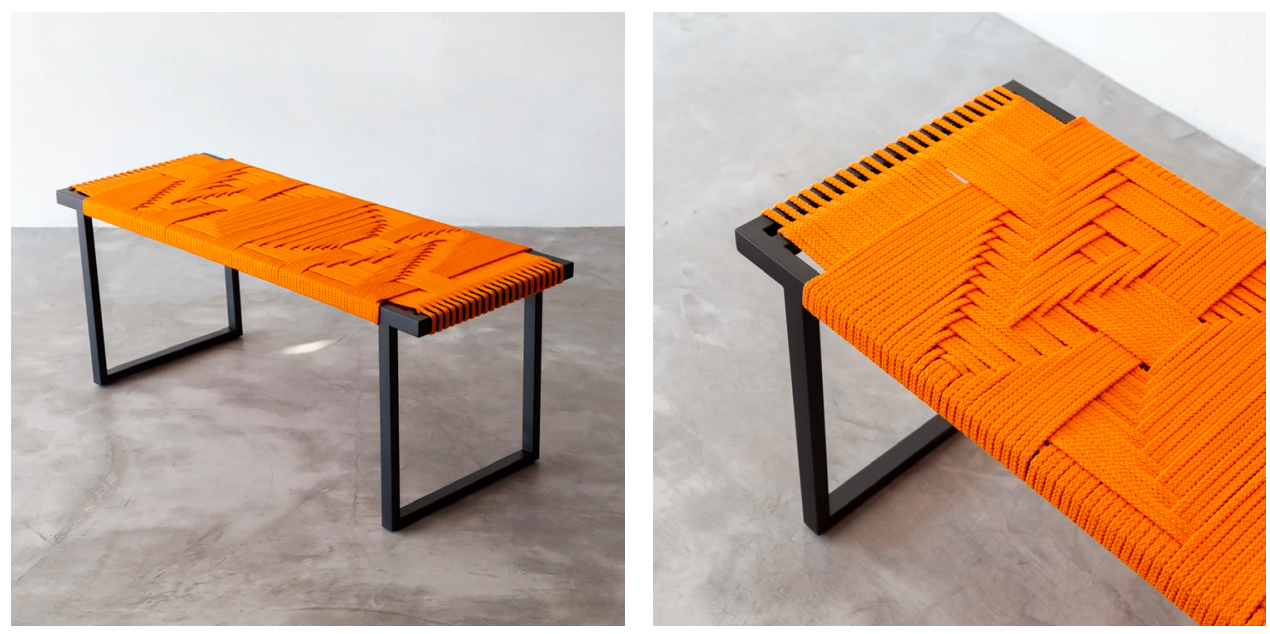

Figuras 5 e 6: Printscreen do vídeo do processo de criação da tessitura que compõe o banco UNA. Studio T44 + Patrick Vargas, 2020. Fonte: Studio T44. Disponível em youtu.be/AekY-jykDDE

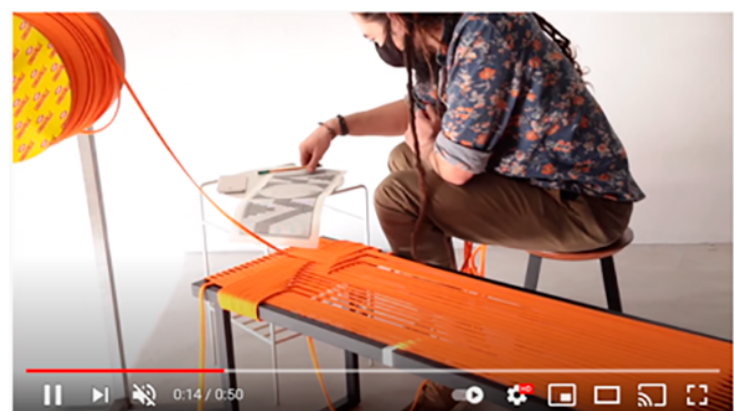

P ta creative studio

$\mathrm{T} 44+$ Patrick Vargas $=$ Banco UNA

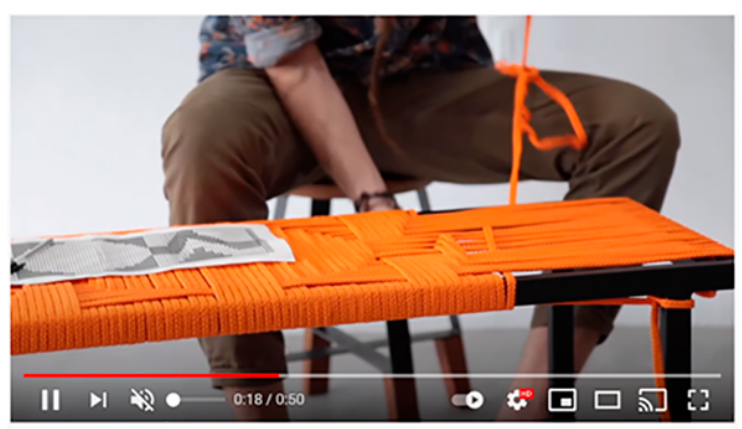

Q t4a creative studio

T44 + Patrick Vargas $=$ Banco UNA

Dentro do mercado editorial independente, a editora Lote 42 se destaca pelo fomento da cena, encabeçando eventos que promovem a cultura do impresso, como a Feira Miolos, e incentivando trocas e relações entre produtores e consumidores. O desejo principal dos editores é tornar este tipo de publicação cada vez mais acessível, formando uma rede entre produtores de grande parte do país e visando iniciativas que, para além das feiras de publicações independentes, façam parte do cotidiano do público e alcancem novos leitores, como seria o caso de bancas e livrarias de rua.

No âmbito das publicações, a Lote 42 possui um catálogo diverso, publicando uma gama variada de temas e gêneros. Entretanto, é destacável a parceria entre a editora e o estúdio de design Casa Rex, co-assinando os projetos com o designer Gustavo Piqueira. São livros onde, por meio de projetos gráficos experimentais, se subvertem os limites da linguagem verbal e visual, traçando fronteiras singelas entre texto e imagem. A artesanalidade aparece como fator de exploração da materialidade física do livro, resultando em objetos dotados de individualidade. 
Como explica a designer Samia Jacintho ${ }^{5}$, sócia de Piqueira na Casa Rex, o método de criação no estúdio corresponde ao citado por Munari e Lupton: trabalhar e testar diversas versões e materiais, arranjos gráficos e tipos de tinta, até que a composição se adeque como linguagem visual do livro em questão. Trazendo o caso de '42 Haicais e 7 Ilustrações', publicado em 2014, verificamos um projeto gráfico que já surge com a proposta de evidenciar a manualidade. As ilustrações internas de FP Rodrigues, feitas à lápis, inspiraram o uso de elementos experimentais e feitos à mão no layout e capa da publicação.

Figuras 7 e 8: Capa e páginas internas de '42 Haicais e 7 ilustrações'. Fonte: Varella, J; Rodrigues, F.P. (2014). 42 Haicais e 7 Ilustrações. São Paulo: Lote 42.
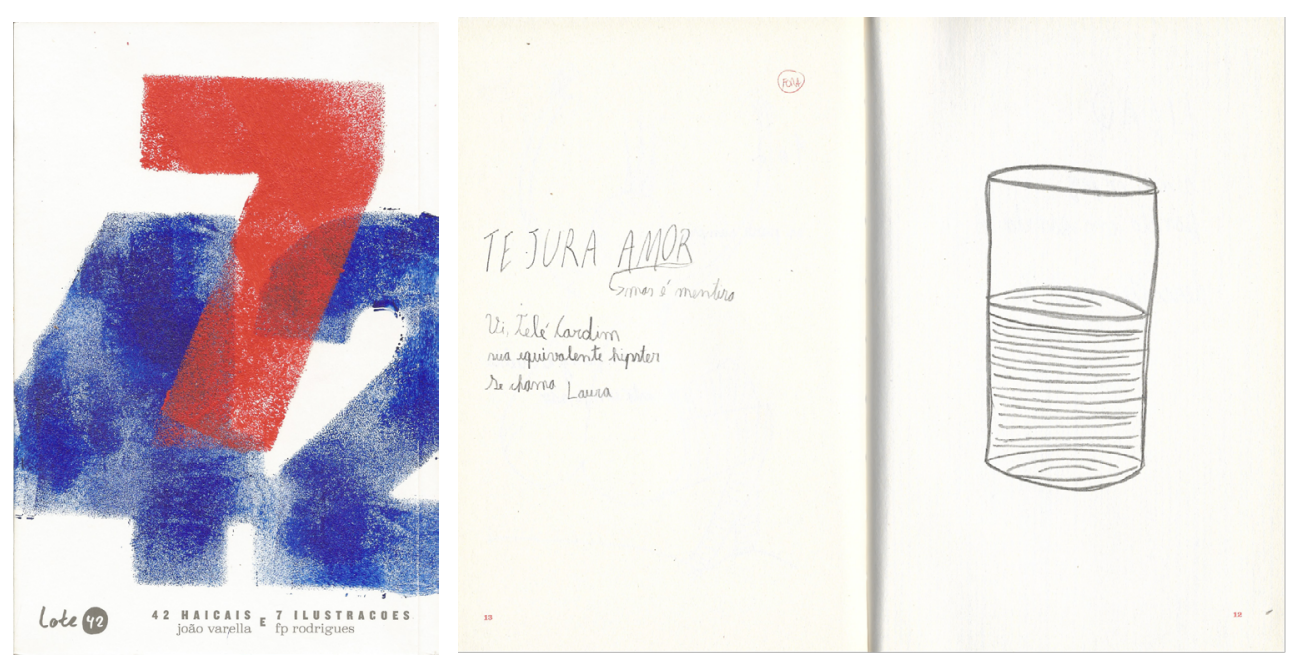

Jacintho comenta que, neste projeto, o autor desejava uma referência aos números do título e, como parte do processo criativo experimental, optou-se pela impressão em stencil, um método até então nunca utilizado pelo estúdio. Na capa em fundo branco, os números foram dispostos aleatoriamente e impressos com rolo e tinta gráfica, cuja densidade traz ao resultado a textura do material e "falhas" particulares do processo. Há uma sobreposição das formas, texturas e cores, trazendo à imagem novas camadas de informação. Devido à impressão manual, é raro que os exemplares sejam reproduzidos perfeitamente e, pela disposição aleatória em cada impressão, demonstra-se a intenção do designer em exacerbar o caráter único de cada exemplar.

\footnotetext{
${ }^{5}$ Em live promovida pelo Laboratório de Design Contemporâneo da UNESP, como parte do evento 'Encontros em Design Contemporâneo 2020'. Ver em: Processos Experimentais da Casa Rex com Samia Jacintho. Disponível em: <youtu.be/KGBV5STI2K0>.
} 
Figuras 9 e 10: O registro do processo criativo demonstra a intenção em evidenciar as particularidades da manualidade e da produção em si. Fonte: Casa Rex. Disponível em: casarex.com/narrativas/42-haicais-e7-ilustracoes
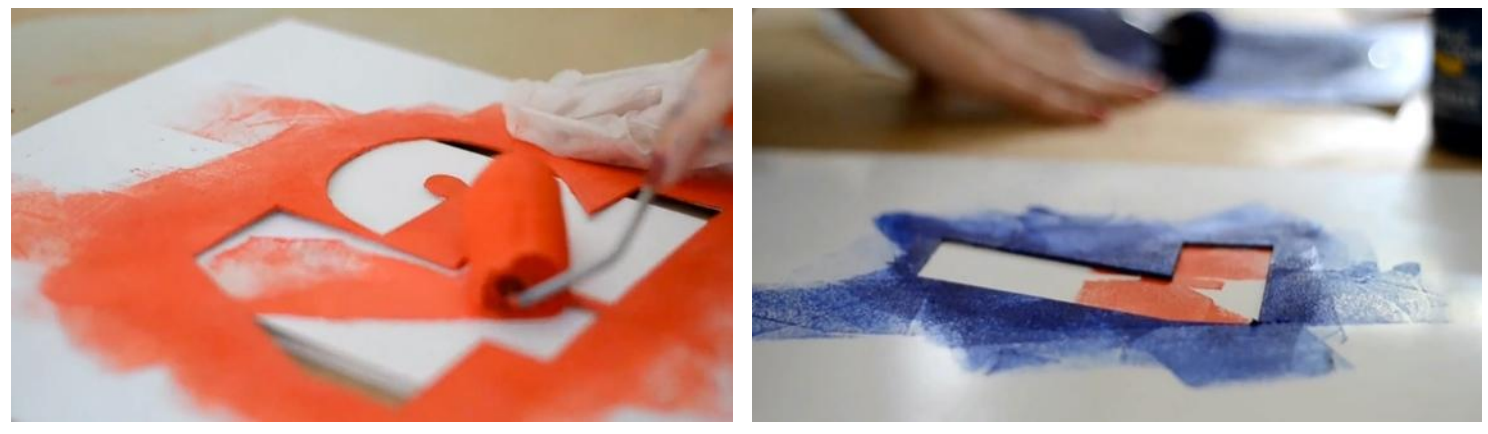

\section{Considerações Finais}

Neste artigo, a contextualização histórica compreendendo os anos 1980 e 1990, assim como o momento contemporâneo, dos anos 2010 a 2020, auxiliaram a compreender o retorno das artes manuais no design brasileiro. A partir dos exemplos evidenciados, dentro de dois campos distintos do design - produto e editorial -, observamos que a reassociação com as artes manuais transcende a dimensão técnica, sendo uma forma de questionamento e reflexão sobre aspectos políticos e sociais como, por exemplo, o consumo.

O ofício manual implica em uma relação poética e natural com o tempo de trabalho, respeitando limites intrínsecos ao corpo, às mãos e ao próprio material. Atualmente, o fazer com as mãos sugere um movimento de fuga ao sistema que preza pela eficiência, alta conectividade e desempenho. Esta maneira de produzir representa ao trabalhador o prazer em fazer algo com as próprias mãos, desenvolvendo suas habilidades técnicas; e ao consumidor, significa a ideia de obter produtos únicos, atrelados a aspectos afetivos e ao consumo consciente - preza-se por objetos fabricados por empresas e produtores de pequeno porte, como artistas, designers e editores, que operam em pequenas escalas e tiragens menores. A partir disto, decorre a satisfação em contribuir com uma causa, como ao apoiar a produção local e "comprar do pequeno". Em ambos os campos, evidenciamos como denominador comum, além do trabalho manual em si, a movimentação em torno de feiras e espaços de venda colaborativa, além de eventos e cursos que estimulam o próprio fazer independente e artesanal.

A recompensa emocional ao contribuir com uma causa, ampliando os discursos atrelados a ela, demonstram que questões coletivas são importantes no contexto da produção contemporânea. Consideravelmente, boa parte dos projetos elaborados que envolvem artes manuais se dão de forma colaborativa - em grupos, duplas e coletivos.

A associação das artes manuais ao design possibilita a criação de objetos que oferecem novas experiências e relações, tanto ao produtor, quanto ao consumidor. Pela riqueza do tema, este trabalho permite desdobramentos que explorem particularmente outros pontos, como a produção coletiva, consumo consciente e o "fazer à mão" compartilhado em redes sociais. 


\section{Referências}

Borges, A. (2011). Design + Artesanato: O caminho brasileiro. São Paulo: Editora Terceiro Nome.

Canclini, N. (2015). Culturas híbridas: estratégias para entrar e sair da modernidade. 4. ed. São Paulo: Edusp.

Crary, J. (2014). 24/7 - Capitalismo tardio e os fins do sono. Sem paginação. São Paulo, Cosac Naify.

Ferrara, L. D. (2011). Desenho Industrial: Da transmissão à tradução. In: Revista Pós. São Paulo, vol. 18 n. 29. p. 68-78.

Flusser, V. (1985) Artifício, Artefato, Artimanha. Curso ministrado na $18^{\mathrm{a}}$ Bienal de São Paulo. Disponível em arquivovilemflussersp.com.br/vilemflusser/wpcontent/uploads/2016/11/flusser-artif\%23U00edcio-artefato-artimanha_new.pdf

Han, B. C. (2015). A sociedade do cansaço. Petrópolis: Vozes.

Jardim Secreto. (n.d.). Sobre o Jardim Secreto. Disponível em www.feirajardimsecreto.com.br/grupo

Lipovetsky, G.; Serroy, J. (2015). A estetização do mundo: viver na era do capitalismo artista. São Paulo: Companhia das Letras.

Lote 42. (n. d.). Sobre a Lote 42. Disponível em lote42.com.br/sobre

Lupton, E. (2008). Indie Publishing: How to design \& produce your own book. Nova York (EUA): Princeton Architectural Press.

Manning, E. (2018). Artimanhas: Coletividades emergentes e processos de individuação. Tradução de André Flogiano e José Antonio R. Magalhães. São Paulo.

Moraes, D. (2005). Análise do Design Brasileiro - Entre mimese e mestiçagem. São Paulo: Blucher.

Moura, M. (2010) Poéticas do Design Contemporâneo: A reinvenção do objeto. III Seminário Nacional de Pesquisa em Cultura Visual, 2010, Goiânia. Anais do III Seminário Nacional de Pesquisa em Cultura Visual. Goiânia: Editora da UFG.

Munari, B. (2016). ¿Cómo nacen los objetos? Apuntes para una metodología proyectual. Barcelona (ESP): Gustavo Gili.

Muniz Jr., J. S. (2016). Girafas e bonsais: editores "independentes" na Argentina e no Brasil (1991-2015). 335f. Tese (doutorado em Sociologia) Orientador: Sergio Miceli Pessôa de Barros. Universidade de São Paulo, São Paulo.

Pedrosa, M. (1995) Arte culta e arte popular. In: Arantes, O. (org.). Política das artes: textos escolhidos I. São Paulo: Edusp, p. 321-332.

Sennett, R. (2009). O Artífice. Rio de Janeiro: Record.

T44. (n.d.) Sobre o T44. Disponível em t44.com.br/pages/sobre-o-estudio 


\section{Sobre as autoras}

Dânica Vasques Fagundes Machado, Mestre em Comunicação e Semiótica, PUC-SP, Brasil <danicavfm@gmail.com>

Maria Luísa Acioli Falcão de Alencar, Doutoranda em Design, FAU-USP, Brasil

<afalencar.marialuisa@usp.br> 